\title{
HOMO SAPIENS ARE BILATERALLY SYMMETRICAL BUT NOT WITH TOE LENGTH AND TOE-LENGTH RATIOS AMONG NIGERIANS
}

\author{
Alabi, A.S ${ }^{1,2}$, Oladipo, G.S ${ }^{2}$, Didia B.C ${ }^{2}$, Aigbogun (Jr), E.O' ${ }^{2}$, Akintunde, K.A \\ ${ }^{1}$ Department of Anatomy, Faculty of Basic Medical Sciences, University of Ilorin.Nigeria. \\ ${ }^{2}$ Department of Anatomy, Faculty of Basic Medical Sciences, University of Port Harcourt.Nigeria. \\ ${ }^{3}$ Department of Psychology, Faculty of Social Sciences, University of Ilorin. Ngeria.
}

Correspondence toA.S Alabi, dradealabi@gmail.com. Department of Anatomy, Faculty of Basic Medical Sciences, University of Ilorin. PMB 1515, Ilorin, Kwara State. Nigeria. +2348030575490

\begin{abstract}
The concept of bilateral symmetry in organisms involves the division of the body plan along a plane that splits the animal's body into right and left sides that are mirror images of each other. However can this be true for toe lengths and ratios? The present study evaluates the symmetric differences in toe length and toe-length ratios among the three major ethnic groups in Nigeria. A total of 1574 adult Nigerian Hausas (664), Igbos (420) and Yorubas (490) of equal sex were included in the study. Aged between 18-65 years, were randomly selected from various states. Written informed consent was taken from each participant, sample size was determined by proportion, using Cochran formulae for infinite population. A digital Vernier caliper was used to obtain direct linear measurements of the toe length of both feet; hallux (1T), second toe (2T), third toe (3T), fourth toe (4T), and the fifth toe (5T). Ten (10) possible toe-length ratios were also determined and named as follows; 1T/2T, 1T/3T, 1T/4T, 1T/5T, 2T/3T, 2T/4T, 2T/5T, 3T/4T, 3T/5T, and 4T/5T. Data were analyzed using SPSS (IBM ${ }^{\circledR}$ Armonk, New York, USA) and Minitab V17 (Minitab ${ }^{\circledR}$ Inc. State College, Pennsylvania) statistical software. Paired-sample t-test was used to evaluate symmetry; Pearson's Correlation was used for inter-prediction of the toes and ratios. Confidence level was set at 95\%; as P-values $\leq 0.05$ were considered significant. The result showed that some of the toe length of both feet were significantly assymetrical among the studied ethnic groups; Hausa males (1T $d f=1.35$ and $5 \mathrm{~T} d f=0.55 ; P<0.05)$ and females (1T and 3T; (1T $d f=0.27,3 \mathrm{~T}$ $d f=0.47) P<0.001)$, Igbo males (1T, 3T and 4T(1T $d f=0.47,3 \mathrm{~T}, d f=-0.53,4 \mathrm{~T} d f=-0.58) ; P<0.05$ and females $1 \mathrm{~T}$ and $3 \mathrm{~T}(1 \mathrm{~T} d f=0.40, \mathrm{~T} 3 d f=-0.64) ; P<0.01)$ and Yoruba males(1T, 2T, 3T and 5T(1T $d f=1.29,2 \mathrm{~T} d f=0.47,3 \mathrm{~T} d f=0.15$, and $5 \mathrm{~T} d f=0.55$ ); $P<0.001)$ and females (1T and 5T(1T $d f=0.77 ; 5 \mathrm{~T} d f=0.23) ; \mathrm{P}<0.001)$. The toe-length ratios also displayed symmetrical differences for Nigerian male population; $1 \mathrm{~T}: 2 \mathrm{~T}[\mathrm{t}=3.78, P<0.001], 1 \mathrm{~T}: 3 \mathrm{~T}[\mathrm{t}=6.27, P<0.001], 1 \mathrm{~T}: 4 \mathrm{~T}[\mathrm{t}=6.04$, $P<0.001], 1 \mathrm{~T}: 5 \mathrm{~T}[\mathrm{t}=2.43, P=0.015], 2 \mathrm{~T}: 3 \mathrm{~T}[\mathrm{t}=2.23, P=0.026], 3 \mathrm{~T}: 5 \mathrm{~T}[\mathrm{t}=-3.78, P<0.001]$ and 4T:5T [t=-3.77, $P<0.001]$. For the female population, all ratios were not significantly different except for1T:4T [t=2.56, $P=0.011]$. However, both feet displayed significant positive association for co-estimation of the corresponding toe length and toe-length ratios ( $r$-values ranging from 0.20 0.70 at $P<0.05)$.Ethnic and sex specific asymmetry were observed in the toe length and toe-length ratios; thus suggesting that anthropometrically, organisms are not completely bilaterally symmetrical.
\end{abstract}

Keywords: Asymmetry, Bilateral symmetry, Toe length, Toe-length ratio, Ethnic groups.

\section{INTRODUCTION}

Humananthropometry is significant in diverse fields as it involves systematic measurements 
of various parts of the body for their quantitative dimension (Kishran, 2006). Bilateral symmetryis referred to as the similarity in the right and left sides of an animal in which any structure on one side of the median place is an image of the same organ on the opposite side. The anteriorposterior or superior-inferior or and cephaliccaudal axis, the two sidesof this axis are the same (symmetrical) (Jordan and Verma, 2011). Many animals have a body form that is symmetrical, meaning that it could be divided into matching halves by drawing a line down the center. In this respect, the right half of a man is a mirror image of its left half - this is called bilateral symmetry $(b i=$ two, latus $=$ side) (Jordan and Verma, 2011).

Researchers has found that men with physical traits commonly associated with masculinity, such as greater height, broader shoulders, and smaller hip-to-waist ratios, tended to have more symmetrical bodies. Similarly, women who were more symmetrical tended to have more typical feminine traits, such as larger hips, longer and more slender legs, and larger breasts (Cloud and Perilloux, 2015). The new finding suggests that the same is true for body symmetry, and that symmetrical proportions could be signs of biological fitness(Cloud and Perilloux, 2015).In animals with two sides that were designed by natural selection to be symmetrical, subtle departures from symmetry may reflect poor development or exposure to environmental or genetic stress," said study team member William Brown of Brunel University in the U.K. In many species these departures are related to poor health, lower survival, and fewer offspring (Willian 2008).

Stress during early development is associated with greater adult bodily asymmetry, as is genetic, inability to deal with the stress (e.g. inbred vs. outbred). This led to the notion that fluctuating asymmetry (FA), deviations from bilateral symmetry in paired traits, randomly distributed to the left and right side, is a measure of developmental instability, i.e., the inability of an organism genetically to buffer the system against stressors to achieve the optimal state, namely symmetry itself (Van, 1962). The key is that if a population shows true FA then it can be presumed to be attempting to be symmetrical, so that failure to do so is a measure of failure to reach, in the face of developmental perturbations, the phenotype that the genotype is aiming for (Trivers et al., 2014).

The main aim of this study is therefore to evaluate symmetric difference in the toe length and toe-length ratios among Nigerian Hausas, Igbos and Yorubas. Therefore, the goals of this investigation is to determine the differences between the toes on the right and left foot, their interpredictability, the differences in the toe-length ratios of the right and left foot and their interpredictability with respect to sex and the the major ethnic groups in Nigeria.

\section{MATERIALS AND METHODS}

A total of 1574 adult Nigerian Hausas (664), Igbos (420) and Yorubas (490) of equally distributed sexes (aged 18-65 years) were randomly selected from various states in Nigeria.Written informed consent was taken from each participant and the sample size was determined by proportion, using Cochran formulae for infinitepopulation $(>10,000) ; S S=\frac{Z^{2} \times p \times q}{d^{2}}$ (Cochran, 1963).Subjects with deformity, injury, fracture, amputation or history of any surgical procedures on toes of both feet, were excluded from the study.
Ethical clearance was obtained from the University of Port Harcourt Ethical Committee (reference number UPH/R\&D/REC/04).

\section{Anthropometric measurements}

Toe length: The length of the toes of the right and left foot were measured using a digital Vernier caliper (with a precision of $0.01 \mathrm{~mm}$ ). The toe lengths were defined as the distance between the tips of the toe till the proximal metatarsophalangeal crease of that toe when fully extended. Each toe was given a number 1T, 2T, 3T, 4T and 5T for hallux, second toe, third toe, fourth toe and fifth toe respectively. The males and females toe lengths were measured twice and the average taken as the 
standard measurements. Measurements were taken by one observer using the same instrument. All measurements were evaluated in millimeters $(\mathrm{mm})$. The toe-length ratios (10 ratios) were calculated by dividing the values of the preceding toes by the next (of the same foot; for both feet) and named as follows; $1 \mathrm{~T} / 2 \mathrm{~T}, 1 \mathrm{~T} / 3 \mathrm{~T}, 1 \mathrm{~T} / 4 \mathrm{~T}, 1 \mathrm{~T} / 5 \mathrm{~T}, 2 \mathrm{~T} / 3 \mathrm{~T}$, $2 \mathrm{~T} / 4 \mathrm{~T}, 2 \mathrm{~T} / 5 \mathrm{~T}, 3 \mathrm{~T} / 4 \mathrm{~T}, 3 \mathrm{~T} / 5 \mathrm{~T}$, and $4 \mathrm{~T} / 5 \mathrm{~T}$.

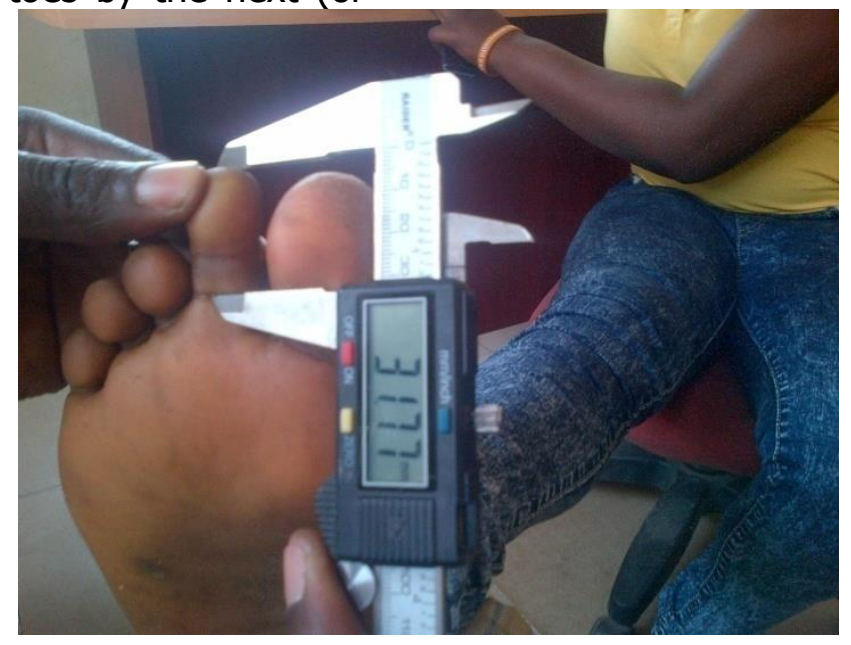

Figure 1: measurement of the $2^{\text {nd }}$ toe length using digital Vernier caliper

\section{Statistical analysis}

SPSS (IBM ${ }^{\circledR}$ Armonk, New York, USA) and Minitab V17 (Minitab ${ }^{\circledR}$ Inc. State College, Pennsylvania) were the statistical packages used in analyzing the obtained data. Pairedsample t-test was used to evaluate toesymmetry; Pearson's Correlation was used for interprediction of the toes and ratios. Confidence level was set at $95 \%$, as P-values $\leq 0.05$ were considered significant.

\section{RESULTS}

The results in Figure 2-4, showed significant dimensional differences in the toe length of the right and left feet (RT and LT) among the different ethnic groups. The toe length showed a directional asymmetry within and between males and females of the three ethnic groups. Majority in favour of the right toes while a few are in favour of the left toes (3T, 4T and 5T in both males and females of Igbos).

The Hausa male population had only the big and little toe lengths which were significantly asymmetrical $\left(1 \mathrm{~T}^{*} d f=1.35, P<0.001\right)$ and $(5 \mathrm{~T}$ $d f=0.55, P<0.001)$ respectively while the left and right $2 \mathrm{~T}, 3 \mathrm{~T}, 4 \mathrm{~T}$ and $5 \mathrm{~T}$ were insignificantly asymmetrical. For the females, 1T $(d f=0.27, P<0.01)$, and T3 $(d f=0.47$, $P<0.001)$ were significantly asymmetrical, while 2T, 4T and 5T were not significantly different $(P>0.05)$. The inter-predictability of corresponding toe length were highly significant $(P<0.001)$ as all male toe length had correlation coefficient $(r)$ values above $0.75 ; \quad 1 \mathrm{~T} \quad(r=0.864), 2 \mathrm{~T} \quad(r=0.827), \quad 3 \mathrm{~T}$ $(r=0.834)$, 4T $(r=0.778)$ and 5T $(r=0.772)$. While for females, correlation $(r)$ values above $\sim \leq 0.75 ; 1 \mathrm{~T} \quad(r=0.752)$, 2T $\quad(r=0.688), 3 \mathrm{~T}$ $(r=0.684)$, 4T $(r=0.638)$ and 5T $(r=0.617)$ (Figure 2). 


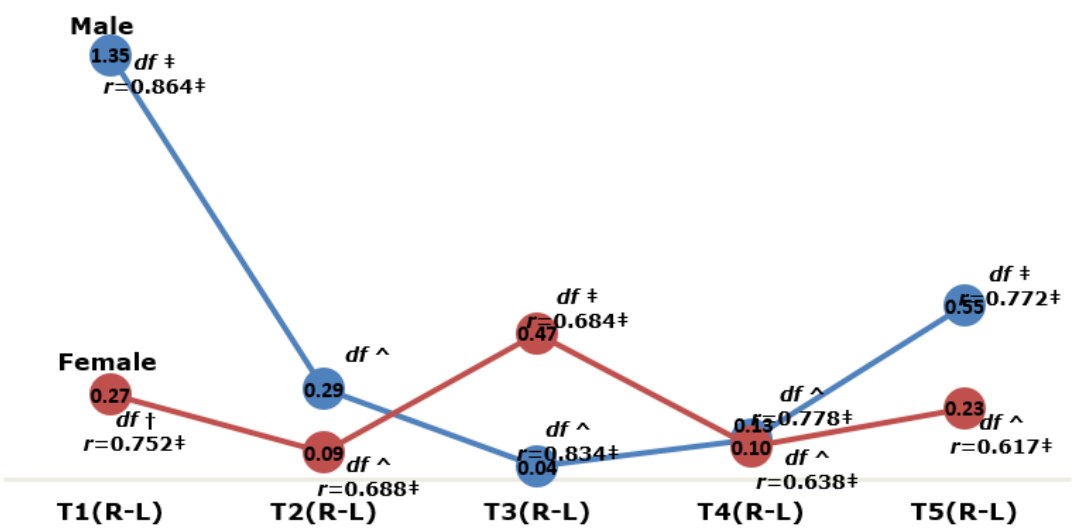

Figure 2: Comparison of the mean difference in left and right toe-length of Hausa population. Note: $T=$ toe-length $(R=$ right and $L=l e f t), d f=$ difference (df insignificant at $\wedge P>0.05$, significant at ${ }^{*} P<0.05,+P<0.01, \neq P<0.001 ; r=P e a r s o n ' s$ correlation; significant at $* \mathrm{P}<0.05,+\mathrm{P}<0.01, \neq \mathrm{P}<0.001)$

For Igbo population, for males, the difference between the left and right toe length were significant for $1 \mathrm{~T}(d f=0.47, P<0.05)$, 3T ( $d f=-$ $0.53, P<0.05)$, 4T $(d f=-0.58, P<0.01)$. The left and right $2 \mathrm{~T}$ and $5 \mathrm{~T}$ were insignificant ( $P>0.05)$; as the correlation between the corresponding left and right toe length were all significant at $\mathrm{P}<0.001$; with high correlation coefficient $(r)$ values; $1 \mathrm{~T}(r=0.79)$, 2T $(r=0.788)$, 3T $(r=0.761), 4 \mathrm{~T}(r=0.864), 5 \mathrm{~T}$ $(r=0.864)$. While for females, $1 \mathrm{~T}(d f=0.40$, $P<0.05)$ and T3 $(d f=-0.64, P<0.01)$ were significantly asymmetrical with correlation $(r)$ values (1T $[r=0.844], 2 \mathrm{~T} \quad[r=0.758], 3 \mathrm{~T}$ [ $r=0.696], 4 \mathrm{~T}[r=0.772]$, and 5T $[r=0.759])$ (Figure 3).
For the Yoruba male population, there were significant differences between the left and right toe lengths $1 \mathrm{~T}(d f=1.29, P<0.001), 2 \mathrm{~T}$ $(d f=0.47, P<0.05), 3 \mathrm{~T}(d f=0.15, P<0.01)$ and 5T $(d f=0.55, P<0.05)$. The left and right 4T was insignificant $(P>0.05)$; as the correlation between the corresponding left and right toe length were all significant at $\mathrm{P}<0.001$. High correlation coefficient $(r)$ values were observed for all variables; 1T $(r=0.723)$, 2T $(r=0.679)$, 3T $(r=0.791)$, 4T $(r=0.816)$, 5T $(r=0.698)$. While for females, $1 \mathrm{~T} \quad(d f=0.77$, $P<0.001)$, and 5T $(d f=0.23, P<0.001)$ were significantly asymmetrical with high correlation $(r)$ values for $1 \mathrm{~T}(r=0.807)$, and 2T $\quad(r=0.819)$, while 3T $\quad(r=0.548)$, 4T $(r=0.556)$ and $\mathrm{T} 5(r=0.58)$ were averagely correlated

(Figure

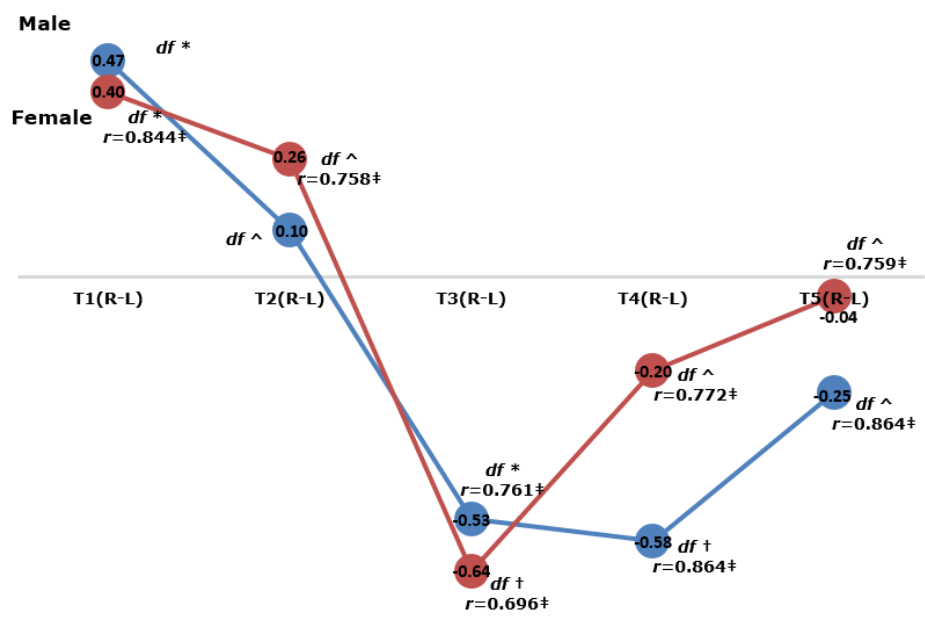

Figure 3: Comparison of the mean difference in left and right toe-length of Igbo population . Note: T=toe-length ( $R=$ right and $L=$ left), $d f=$ difference (df insignificant at $\wedge P>0.05$, significant at $* P<0.05,+P<0.01, \neq P<0.001 ; r=P$ earson's correlation; significant at $* \mathrm{P}<0.05,+\mathrm{P}<0.01, \neq \mathrm{P}<0.001)$ 
The paired sample t-test in Tables $1,2 a \& b$ showed that there were significant intraindividual side differences in toe-length ratios for the Nigerian population. Marked significant greater toe-length ratio was observed for right side (1T:2T $[\mathrm{t}=3.48, P=0.001], 1 \mathrm{~T}: 3 \mathrm{~T}$ $[\mathrm{t}=4.56, P<0.001], 1 \mathrm{~T}: 4 \mathrm{~T}[\mathrm{t}=5.88, P<0.001]$, $2 \mathrm{~T}: 4 \mathrm{~T}[\mathrm{t}=2.27, P=0.023])$. But, the left toelength ratios were significantly greater than the right for $3 \mathrm{~T}: 5 \mathrm{~T}[\mathrm{t}=-2.84, P=0.005]$ and 4T:5T [t=-3.91, $P<0.001]$; while 1T:5T, $2 \mathrm{~T}: 3 \mathrm{~T}, 2 \mathrm{~T}: 5 \mathrm{~T}$, and $3 \mathrm{~T}: 4 \mathrm{~T}$ were not significantly different $(P>0.05)$ (Table 1$)$. Symmetric differences were observed in the toe-length ratios of Nigerian male population; with greater right foot values for $1 \mathrm{~T}: 2 \mathrm{~T}$ $[\mathrm{t}=3.78, P<0.001], 1 \mathrm{~T}: 3 \mathrm{~T}[\mathrm{t}=6.27, P<0.001]$, 1T:4T $\quad[\mathrm{t}=6.04, P<0.001], \quad 1 \mathrm{~T}: 5 \mathrm{~T} \quad[\mathrm{t}=2.43$, $P=0.015], 2 \mathrm{~T}: 3 \mathrm{~T}[\mathrm{t}=2.23, P=0.026]$; whereas, 3T:5T [t=-3.78, $P<0.001], 4 \mathrm{~T}: 5 \mathrm{~T}[\mathrm{t}=3.77$,

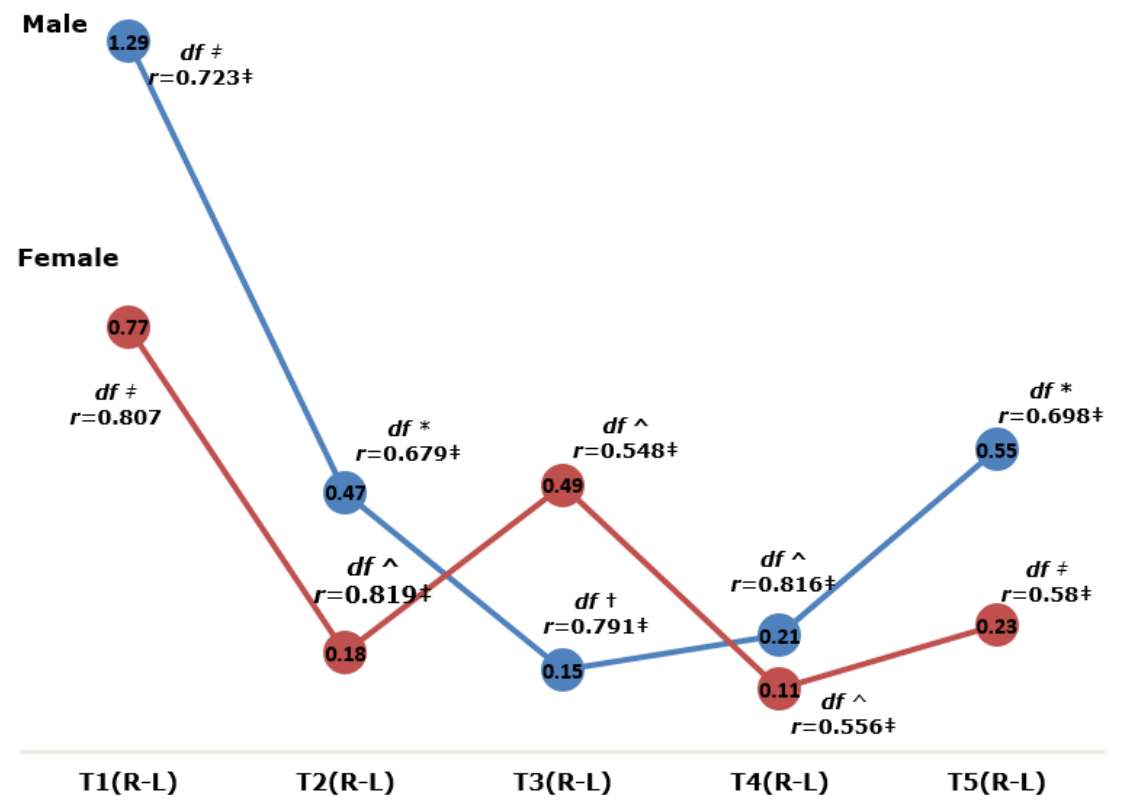

$P<0.001]$ were lower in the right foot (Table 2a). Conversely, the differences in the toelength ratios of the female population were invariably insignificant except for 1T:4T $[\mathrm{t}=2.56, P=0.011]$ which was larger in the right when compared to the corresponding left (Table 2b).

From the paired sample correlation of toelength ratios, both feet displayed significant association for co-estimation of corresponding ratios. In decreasing order of predictability, for the general population, the following toelength ratios had correlation $(r)$ values above average $(>50) ; 1 \mathrm{~T}: 5 \mathrm{~T} \quad(r=0.746), \quad 2 \mathrm{~T}: 5 \mathrm{~T}$ $(r=0.671), 1 \mathrm{~T}: 4 \mathrm{~T}(r=0.670), 1 \mathrm{~T}: 2 \mathrm{~T}(r=0.637)$, 1T:3T $\quad(r=0.625), 3 \mathrm{~T}: 5 \mathrm{~T} \quad(r=0.613)$ while 2T:4T was average with $r=0.508$, and $4 \mathrm{~T}: 5 \mathrm{~T}$ $(r=0.451), 2 \mathrm{~T}: 3 \mathrm{~T}(r=0.383), 3 \mathrm{~T}: 4 \mathrm{~T}(r=0.331)$ were low $(<0.5) \quad($ Table 1$)$.
Figure 4: Comparison of the mean difference in left and right toe-length of Yoruba population. Note: T=toe-length ( $R=$ right and $L=$ left), $d f=$ difference ( $d f$ insignificant at $\wedge P>0.05$, significant at $* P<0.05, \quad+P<0.01, \neq P<0.001$; $r=$ Pearson's correlation; significant at $* P<0.05,+P<0.01, \neq P<0.001)$
For male population, the correlation between the left and right toe-length ratio was rather poor with only $1 \mathrm{~T}: 4 \mathrm{~T}$ and $1 \mathrm{~T}: 5 \mathrm{~T}$ having $r-$ values close to $60 \%(0.60)$; all other measured variables were between average (1T:2T [r=0.59], 1T:3T $\quad[r=0.58], \quad 2 \mathrm{~T}: 5 \mathrm{~T}$ $[r=0.57])$ and low $(2 \mathrm{~T}: 4 \mathrm{~T}[r=0.47], 3 \mathrm{~T}: 5 \mathrm{~T}$ $[r=0.45], 2 \mathrm{~T}: 3 \mathrm{~T} \quad[r=0.43], 4 \mathrm{~T}: 5 \mathrm{~T} \quad[r=0.36]$,
3T:4T [ $r=0.24]$ ) (Table 2a). For the female population, better correlation was observed and this was associated with the indifference in values observed for both feet thus increasing the strength of co-estimation. Six variables $(1 \mathrm{~T}: 2 \mathrm{~T}, 1 \mathrm{~T}: 3 \mathrm{~T}, 1 \mathrm{~T}: 4 \mathrm{~T}, 1 \mathrm{~T}: 5 \mathrm{~T}, 2 \mathrm{~T}: 5 \mathrm{~T}$, $3 \mathrm{~T}: 5 \mathrm{~T})$ had $r$-values greater than $60 \%$ and two variables on average correlation (2T:4T 
[ $r=0.54]$ and 4T:5T $\quad[r=0.52])$ while the remaining two ratios (2T:3T $[r=0.33]$, and 3T:4T $[r=0.41]$ ) were low (Table $2 b$ ). It must be noted that all analyzed paired samples were significant positively correlated at $\mathrm{P}<0.001$.

The symmetric evaluation and predictions of the toe-length ratios among the tribes illustrated in Figure 5 was derived by a paired t-test and the results showed that: The Hausa population had four toe-length ratios which appeared significantly different $\left(1 \mathrm{~T}: 2 \mathrm{~T}^{*} d f=0.014, \quad P<0.01,1 \mathrm{~T}: 3 \mathrm{~T}^{*} d f=0.009\right.$, $P<0.01,2 \mathrm{~T}: 5 T^{*} d f=0.014 \quad P<0.01,1 \mathrm{~T}: 5^{*} *$ $d f=0.014 P<0.01$ ), while the remaining toelength ratios were insignificantly asymmetrical. In determining the interpredictability of corresponding ratios, all toelength ratios were highly significant $(P<0.001)$ as ratios involving the big toe (1T) had correlation $(r$ ) values above average $(>65)$; 1T:2T $\quad(r=0.70), 1 \mathrm{~T}: 3 \mathrm{~T} \quad(r=0.669), 1 \mathrm{~T}: 4 \mathrm{~T}$ $(r=0.659)$, 1T:5T $(r=0.6777)$, the small toe had $r$-values from $0.50-0.65$ (2T:5T $[r=0.623], \quad 3 \mathrm{~T}: 5 \mathrm{~T} \quad(r=0.645)$ and $4 \mathrm{~T}: 5 \mathrm{~T}$ $(r=0.646)$, while 2T:3T $(r=0.441), \quad 2 \mathrm{~T}: 4 \mathrm{~T}$ $(r=0.497)$ and 3T:4T $(r=0.295)$, were low $(<0.5)$.

For Igbo population, the difference between the left and right toe-length ratio was significant for only R1T:4T ( $d f=0.026$, $P<0.05)$, for others, the difference observed were insignificant $(P>0.05)$ and the correlation between the corresponding left and right toe-length ratios were significant at $\mathrm{P}<0.001$; with correlation $(r)$ values falling just above average and lower. However, all toe-length ratios involving the big toe (1T) had $(r)$ values above average $(>50) ; 1 \mathrm{~T}: 2 \mathrm{~T}$ $(r=0.58)$, 1T:3T $(r=0.593), 1 \mathrm{~T}: 4 \mathrm{~T} \quad(r=0.56)$, 1T:5T $(r=0.578)$. The small toe-length ratios had average correlation $(r \sim=50) ; 2 T: 5 T$ $(r=0.524), \quad 3 \mathrm{~T}: 5 \mathrm{~T} \quad(r=0.561) \quad$ and $4 \mathrm{~T}: 5 \mathrm{~T}$ $(r=0.48)$, while 2T:3T $(r=0.234), \quad 2 \mathrm{~T}: 4 \mathrm{~T}$ $(r=0.402)$ and 3T:4T $(r=0.221)$, were low $(<0.5)$.

For Yoruba population, the first three toelength ratios involving the big toe (1T) were significantly asymmetrical $(1 \mathrm{~T}: 2 \mathrm{~T} * d f=0.016$, $P<0.01 ; \quad 1 \mathrm{~T}: 3 \mathrm{~T}^{*} d f=0.018, \quad P<0.05 ; \quad 1 \mathrm{~T}: 4 \mathrm{~T}^{*}$ $d f=0.030, \quad P<0.01)$. All corresponding toelength ratios prediction were significant $(P<0.001)$ with better correlation when compared with the Igbo values. The four variables involving the big toe had the highest ( $r$ ) values (1T:2T [ $r=0.676], 1 \mathrm{~T}: 3 \mathrm{~T}[r=0.651]$, 1T:4T [ $r=0.670], 1 \mathrm{~T}: 5 \mathrm{~T}[r=0.623])$, followed by the small toe ratios (2T:5T [ $r=0.609]$, 3T:5T $[r=0.545])$ and then the fourth toe (4T) $(2 \mathrm{~T}: 4 \mathrm{~T}[r=0.518], 4 \mathrm{~T}: 5 \mathrm{~T}[r=0.489])$.

Table 1: Symmetric differences in toe-length ratio (general population, $N=1574$ )

\begin{tabular}{|c|c|c|c|c|c|c|}
\hline \multirow[t]{2}{*}{ Paired Sample } & \multicolumn{2}{|c|}{ Paired Differences } & \multicolumn{2}{|c|}{ Test of mean difference } & \multicolumn{2}{|c|}{ Correlation } \\
\hline & Mean & S.D & t-value & P-value & $r$ & P-value \\
\hline R1T:2T - L1T:2T & 0.012 & 0.14 & 3.48 & 0.001 & 0.637 & $<0.001$ \\
\hline R1T:3T - L1T:3T & 0.022 & 0.19 & 4.56 & $<0.001$ & 0.625 & $<0.001$ \\
\hline R1T:4T - L1T:4T & 0.034 & 0.23 & 5.88 & $<0.001$ & 0.670 & $<0.001$ \\
\hline R1T:5T - L1T:5T & 0.012 & 0.26 & 1.79 & 0.074 & 0.746 & $<0.001$ \\
\hline R2T:3T - L2T:3T & 0.004 & 0.15 & 1.09 & 0.278 & 0.383 & $<0.001$ \\
\hline R2T:4T - L2T:4T & 0.011 & 0.19 & 2.27 & 0.023 & 0.508 & $<0.001$ \\
\hline R2T:5T - L2T:5T & -0.007 & 0.22 & -1.34 & 0.179 & 0.671 & $<0.001$ \\
\hline R3T:4T - L3T:4T & 0.003 & 0.15 & 0.92 & 0.356 & 0.331 & $<0.001$ \\
\hline R3T:5T - L3T:5T & -0.013 & 0.18 & -2.84 & 0.005 & 0.613 & $<0.001$ \\
\hline R4T:5T - L4T:5T & -0.014 & 0.14 & -3.91 & $<0.001$ & 0.451 & $<0.001$ \\
\hline
\end{tabular}

Note:R=Right, $L=L$ eft, $T=$ Toes, RF=Right foot, $L F=$ Left foot, RFL=Right foot length, $L F L=L e f t$ foot length, $T=T o e$; $\mathrm{S} . \mathrm{D}=$ Standard deviation; $\mathrm{t}$-value=t-calculated value; $\mathrm{P}$-value=Probability value; $r=$ Pearson's correlation coefficient 
Table 2a: Symmetric differences in toe-length ratio of the male population

\begin{tabular}{|l|l|l|l|l|l|l|}
\hline \multirow{2}{*}{ Paired Sample } & \multicolumn{2}{l|}{ Paired Differences } & \multicolumn{2}{l|}{ Test of mean difference } & \multicolumn{2}{l|}{ Correlation } \\
\cline { 2 - 7 } & Mean & S.D & t-value & P-value & $r$ & P-value \\
\hline R1T:2T - L1T:2T & 0.018 & 0.14 & 3.78 & $<0.001$ & 0.59 & $<0.001$ \\
\hline R1T:3T - L1T:3T & 0.041 & 0.19 & 6.268 & $<0.001$ & 0.58 & $<0.001$ \\
\hline R1T:4T - L1T:4T & 0.045 & 0.21 & 6.043 & $<0.001$ & 0.60 & $<0.001$ \\
\hline R1T:5T - L1T:5T & 0.019 & 0.22 & 2.427 & 0.015 & 0.61 & $<0.001$ \\
\hline R2T:3T - L2T:3T & 0.012 & 0.15 & 2.227 & 0.026 & 0.43 & $<0.001$ \\
\hline R2T:4T - L2T:4T & 0.014 & 0.19 & 2.059 & 0.040 & 0.47 & $<0.001$ \\
\hline R2T:5T - L2T:5T & -0.011 & 0.20 & -1.447 & 0.148 & 0.57 & $<0.001$ \\
\hline R3T:4T - L3T:4T & -0.002 & 0.15 & -0.286 & 0.775 & 0.24 & $<0.001$ \\
\hline R3T:5T - L3T:5T & -0.024 & 0.18 & -3.782 & $<0.001$ & 0.45 & $<0.001$ \\
\hline R4T:5T - L4T:5T & -0.019 & 0.14 & -3.765 & $<0.001$ & 0.36 & $<0.001$ \\
\hline
\end{tabular}

Note:R=Right, $L=L e f t, T=T o e s, R F=R i g h t$ foot, $L F=L e f t$ foot, RFL=Right foot length, $L F L=L e f t$ foot length, $T=$ Toe; $\mathrm{S} . \mathrm{D}=$ Standard deviation; $\mathrm{t}$-value=t-calculated value; $\mathrm{P}$-value=Probability value; $r=$ Pearson's correlation coefficient

Table 2b: Symmetric differences in toe-length ratio of female population

\begin{tabular}{|l|l|l|l|l|l|l|}
\hline \multirow{2}{*}{ Paired Sample } & \multicolumn{2}{l}{ Paired Differences } & \multicolumn{2}{l|}{ Test of mean difference } & \multicolumn{2}{l|}{ Correlation } \\
\cline { 2 - 7 } & Mean & S.D & t-value & P-value & $r$ & P-value \\
\hline R1T:2T - L1T:2T & 0.006 & 0.14 & 1.187 & 0.235 & 0.64 & $<0.001$ \\
\hline R1T:3T - L1T:3T & 0.002 & 0.19 & 0.360 & 0.719 & 0.63 & $<0.001$ \\
\hline R1T:4T - L1T:4T & 0.022 & 0.24 & 2.557 & 0.011 & 0.68 & $<0.001$ \\
\hline R1T:5T - L1T:5T & 0.004 & 0.29 & 0.385 & 0.700 & 0.77 & $<0.001$ \\
\hline R2T:3T - L2T:3T & -0.004 & 0.15 & -0.692 & 0.489 & 0.33 & $<0.001$ \\
\hline R2T:4T - L2T:4T & 0.008 & 0.20 & 1.177 & 0.240 & 0.54 & $<0.001$ \\
\hline R2T:5T - L2T:5T & -0.004 & 0.23 & -0.505 & 0.613 & 0.72 & $<0.001$ \\
\hline R3T:4T - L3T:4T & 0.008 & 0.14 & 1.659 & 0.097 & 0.41 & $<0.001$ \\
\hline R3T:5T - L3T:5T & -0.002 & 0.18 & -0.255 & 0.799 & 0.70 & $<0.001$ \\
\hline R4T:5T - L4T:5T & -0.009 & 0.14 & -1.795 & 0.073 & 0.52 & $<0.001$ \\
\hline
\end{tabular}

Note:R=Right, $L=L e f t, T=T o e s, R F=R i g h t$ foot, $L F=L e f t$ foot, RFL=Right foot length, LFL=Left foot length, T=Toe; $\mathrm{S} . \mathrm{D}=$ Standard deviation; $\mathrm{t}$-value=t-calculated value; $\mathrm{P}$-value=Probability value; $r=$ Pearson's correlation coefficient

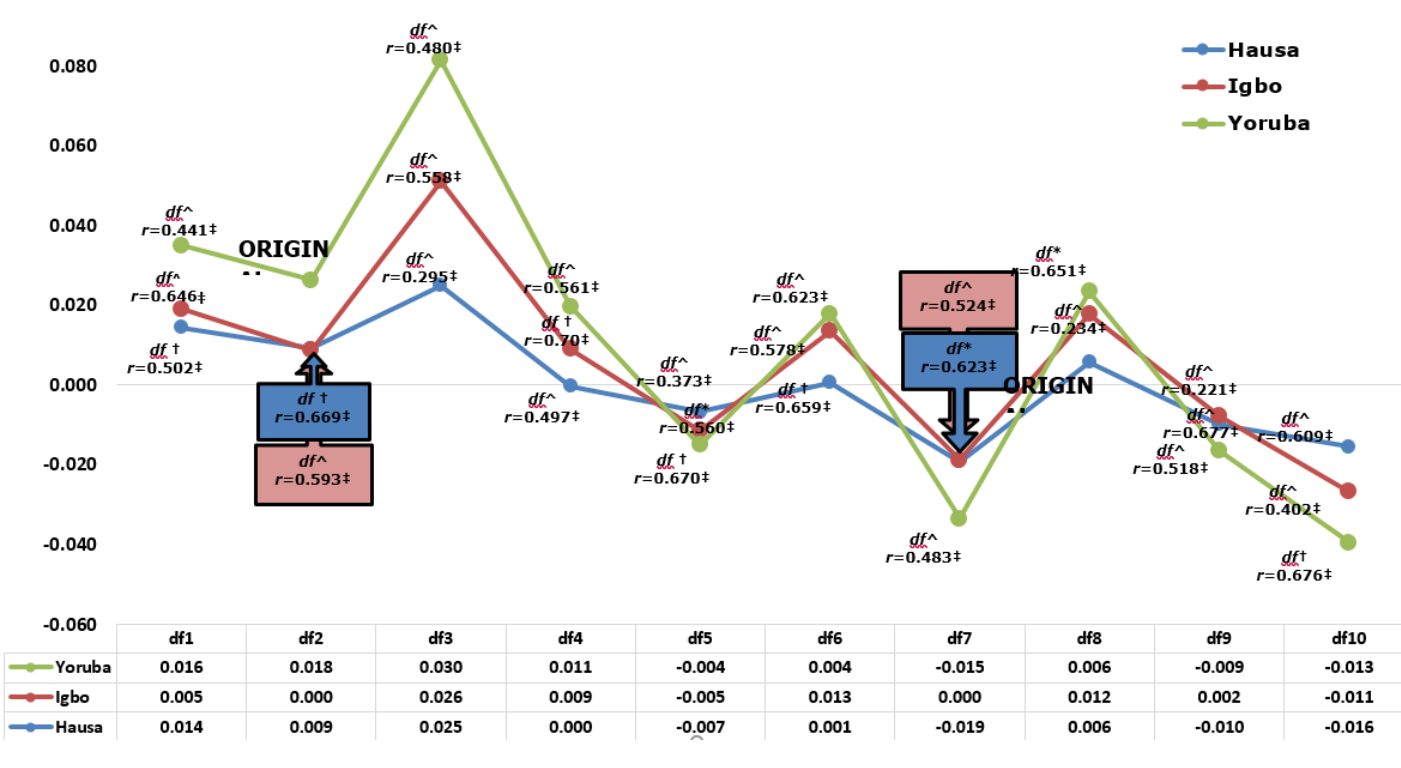

Figure 5: Line graph of mean differences of the left and right toe-length ratios of the studies populations. $\mathrm{df}=$ difference; df1=R1T:2T-1LT:2T; df2=R1T:3T-L1T:3T; df3=R1T:4T-L1T:4T; df4=R1T:5T-L1T:5T; df5=R2T:3T-L2T:3T; df6=R2T:4T-L2T:4T; df7=R2T:5T-L2T:5T; df8=R3T:4T-L3T:4T; df9=R3T:5T-L3T:5T; df10=R4T:5T-L4T:5T (df significant at $\wedge P>0.05, \quad * P<0.05$, $+\mathrm{P}<0.01 ; \quad r=$ Pearson's correlation; significant at $* P<0.05,+P<0.01, \neq$ $\mathrm{P}<0.001$ 


\section{DISCUSSION}

Bilateralism:In its original concept in organism dealt with the presence in equal halves of the organism; however with the advent of anthropometry it was observed that such assumptions may not be accurate as various anatomical structures has shown differences in morphology and anthropometry and this has shown to significantly influence function.E.g Bronchus, hand size and grip strength, foot power (Claes et al., 2012).

\section{Asymmetry}

The difference in corresponding paired anatomical structures havebeen a subject of research in body symmetry studies in order to explain the influence of various developmental favouritism (Steele and Mays,1995; Voracek et al., 2007), brain lateralization(Steele,2000)as well as the influences of diverse environmental factors and culture(Oladipo et al., 2016). Findings from these studies have been used to explain various concepts of use and disuse of the body parts with preference to size, position, and functionality (Oladipo et al., 2016). Voraceket al. (2007) described clearly the concept of asymmetry in foot dimensions as they enunciated that such asymmetry occurs in individuals due to the effect of foetal androgens, which to a large extent appeared to favour the development of the right side of the body over the left side for males. But the converse in females.In this study, the relative similarity in the mean values of the left and right toe lengths would have suggested bilateral symmetry in the toe lengths; however when tested, the difference in the mean values were significant; even among the three studied populations (Hausa, Igbo and Yoruba). For the Hausa and Yoruba populations, the difference observed favoured the toes in the right foot; in line with the postulation of Voracek et al. (2007) while the Igbo population defied such postulation (with greater left values for $3 \mathrm{~T}, 4 \mathrm{~T}$ and $5 \mathrm{~T}$ ). However the sex-related foot-length asymmetry as documented by Voracek et al. (2007) was inconsistent as observed in this study; but the findings of this study was in line with the postulation by Baron-Cohen (2003) and the findings of Abledu et al. (2015)on Ghanaians; as they documented significant bilateral asymmetry in the foot print dimensions which was not sex specific in its pattern.

Hence this study showed a directional asymmetry within and between sexes implying it's usage as a guide in plastic and reconstruction surgery. Hand strength is affected by hand size which is a factor for hand grip strength, therefore in lower limb using prehensile foot, it may not be surprising that foot with the greatest strength for movement is the larger one in size, the length inclusive (Sathian et al., 2011).Also in unilateral foot diseases, disorders and damages, the existence of asymmetry will imply that the opposite foot cannot be used for reconstruction since they are not mirror images as suggested in Concept of Symmetrical Bilaterality (Sforza et al., 1998).

Also the toe-length ratios showed marked differences between the left and right sides especially with ratios involving the halux (1T). This also showed directional asymmetry which has sex pattern. This can serve as adjunct to the use of asymmetry in toe length in orthopaedics as well as in plastic and reconstruction surgery.

\section{Interpredictability}

Though the differences in the mean values of some toes where significant, however corresponding toes of the feet could significantly predict each other. This shows that development of paired body parts despite not being mirror images could still be used for reconstructive guidance and inferential analysis.Alsothe correlation between the corresponding toe-length ratios were high and significant for the above mentioned toe-length ratios. Thus the finding suggests that the derived relationships between toe-length ratios would provide better comparative predictions if the halux is involved.

The observed variability in the difference in the mean values as well as the difference in the inter-predictability levels of the toe-length 
ratios affirms the findings that suggested ethnic and sex differences in foot dimensions in studies involving secular change and allometry (Meadows, 1996; Meadows and Jantz 1999)which observed sex and population related differential limb proportions. The findings and inferences from the asymmetry of the toe length and toelength ratios, in this study can help in reconstruction and orthopaedic surgery of the toes. As well as in the knowledge of human variation.
In conclusion, this study observed asymmetry in the toe length as well as the toe-length ratios of males and females of the studied ethnic groups in Nigeria; thus suggesting that humans may appear bilaterally symmetrical; but anthropometrically, are not completely bilaterally symmetrical which may indeed affect function and use of body parts. This study will find use in orthopaedic, Plastic and constructive surgery of the toes and in the understanding of human variation.

\section{REFERENCES}

1. Abledu JK, Abledu GK, Offei EB, Antwi EM. 2015. Determination of sex from foot print dimensions in a Ghana population PLOS ONE 10(1371): 2-9.

2. Baron-Cohen S. 2003. The essential difference: The truth about the male and female brain. Basic Book Publisher, New York, USA, Pp 30-116.

3. Claes P, Daniels K, Walters M, Clements J, Vandermeulen D, Suetens P. 2012. Dysmorphometrics: the modelling of morphological abnormalities. Theoretical Biology and Medical Modelling 9:5.

4. Cloud JM, Perilloux C. 2015. "Drawing" Conclusions about Perceptions of Ideal Male and Female Body Shapes. Evolutionary Psychological Science 1(3):163-171.

5. Cochran WG. 1963. Sampling techniques (2nd edition). New York: John wiley and sons, Inc. Pp 2-5.

6. Jordan EL, Verma PS.2011. Chordate Zoology. $11^{\text {th }}$ Edition. S. Chand \& Company Ltd, New Delhi Pp 2-3.

7. Krishan K. 2006. Anthropometry in Forensic Medicine and Forensic Science-'Forensic Anthropometry'. The Internet Journal of Forensic Science 2:1.

8. Meadows L.1996. Secular change and allometry in the long limb bones of Americans from the mid 1700 through the 1970s (dissertation). University of Tennese, Knoxville, Tennese.

9. Meadows L, Jantz RL. 1999. Secular changes in long bone length and proportion in the United States 1800-1970. American Journal of Anthropology 110: 57-67.

10. Oladipo GS, Aigbogun (Jr) EO, Akani LG. 2016. Determination of handedness: An anthropometric evaluation of the glenoid cavity. Annals of Bioanthropology 4(1):20-25.

11. Sathian K, Buxbaum L, Cohen LG, Krakauer JW, Lang CE, Corbetta M, Fitzpatric SM. 2011. Neurological Principles and Rehabilitation of Action Disorders: Common Clinical Deficits. Neurorehabil Neural Repair 25(5): 21-25.

12. Sforza C, Michielon G, Fragnito N, Ferrario VF. 1998. Foot asymmetry in healthy adults: elliptic fourier analysis of standardized foot print. Journal of Orthopaedic Research 16(6):758-765.

13. Steele J, Mays S. 1995. Handedness and directional asymmetry in the long bones of the human upper limb. International Journal of Osteoarchaeology 5: 39-49.

14. Steele J. 2000. Handedness in past human populations: Skeletal markers. Laterality 5: 193-220.

15. Trivers R, Fink B, Russell M, McCarty K, James B, Palestis BG. 2014. Lower Body Symmetry and Running Performance in Elite Jamaican Track and Field Athletes. PLoS ONE 9(11): 113106.

16. Van VL. 1962. A study of fluctuating asymmetry. Evolution 16: 125-142.

17. Voracek M, Fisher ML, Rupp, B, Lucas D, Fessler DMT. 2007. Sex differences in relative foot length and perceived attractiveness of female feet: Relationships among anthropometry, physique, and preference ratings. Perceptual and Motor Skills 104: 1123-1138.

18. William B. 2008. Why Symmetry Predicts Bodily Attractiveness. https://www.sciencedaily.com. Retrieved August 19, 2008. 